\title{
Decrease in malonyl-CoA and its background metabolic alterations in murine model of cancer cachexia
}

\author{
ALPER CELIK $^{2,4}$, YOSHIHIKO KANO ${ }^{2}$, SHINGO TSUJINAKA ${ }^{2}$, SINICHIROU OKADA $^{2}$, \\ KOICHI TAKAO ${ }^{5}$, MASAKAZU TAKAGI ${ }^{6}$, SHIGERU CHOHNAN ${ }^{6}$, \\ KUNIYASU SODA $^{1,2}$, MASANOBU KAWAKAMI ${ }^{3}$ and FUMIO KONISHI ${ }^{2}$
}

\begin{abstract}
Departments of ${ }^{1}$ Cardiovascular Research Institute and ${ }^{2}$ Surgery, Saitama Medical Center, and ${ }^{3}$ Internal Medicine, Saitama Medical Center, Jichi Medical University, Saitama, Japan; ${ }^{4}$ Department of Surgery, Gaziosmanpasa University, Faculty of Medicine, Turkey; ${ }^{5}$ Department of Clinical Dietetics \& Human Nutrition, Faculty of Pharmaceutical Sciences, Josai University, Saitama; ${ }^{6}$ Department of Bio-resource Science, Ibaraki University College of Agriculture, Ibaraki, Japan
\end{abstract}

Received December 1, 2008; Accepted January 12, 2009

DOI: $10.3892 /$ or_00000330

\begin{abstract}
The alterations of enzymatic activities involved in lipid degradation in cancer cachexia have not been fully elucidated. One of the two subclones of colon 26 adenocarcinoma, clone 20 , with a potent ability to induce cachexia, or clone 5, without such an activity, was transplanted in to CDF-1 male mice. Murine livers were extirpated for analyses on the 14th day after tumor inoculation. The body weights and food intake of mice bearing clone 20 were all significantly lower than those of non-tumor bearing mice and mice bearing the clone 5 tumor. The decline of body weight was accompanied by a shrinkage of epididymal fat pads. Expression of spermidine/spermine N-1 acetyl transferase (SSAT) assessed by real-time PCR was significantly increased in cachectic mice. Conversely, acetyl-CoA carboxylase (ACC) measured by Western blotting and malonyl-CoA levels determined by malonyl-CoA:acetyl-CoA cycling procedures were decreased in cachectic mice. Indomethacin in drinking water reversed the clone 20 induced decrease in body and fat weight and food intake, and simultaneously negated the clone 20 induced increase of SSAT expressions and decrease of ACC and malonyl-CoA amounts. Because malonyl-CoA inhibits the rate-limiting step in the beta-oxidation of fatty acids, the decreased malonyl-CoA and the background metabolic alterations may contribute to the accelerated lipolysis of cancer cachexia.
\end{abstract}

Correspondence to: Dr Kuniyasu Soda, Department of Cardiovascular Research Institute and Surgery, Saitama Medical Center, 1-847 Amanuma, Omiya, Saitama-city, Saitama 330-8503, Japan

E-mail: soda@jichi.ac.jp

Key words: malonyl-CoA, cancer cachexia, polyamine, spermidine/ spermine N-1 acetyl transferase

\section{Introduction}

Cancer anorexia-cachexia syndrome is a condition characterized by a constellation of nutritional abnormalities leading to progressive wasting and weakness observed in cancer patients (1). Body weight loss, an easily recognizable symptom of cancer cachexia, is characterized by a decline in the weight of storage fat (lipolysis). While body weight loss is often accompanied with a reduction of food intake, animal experiments have clearly shown that lipolysis is not simply attributable to a decreased caloric intake. Considerable efforts have been made to elucidate the pathogenesis of cancer cachexia and have shown that many factors are involved $(2,3)$. Among them, pro-inflammatory cytokines, hormones, and several characteristic cachexia-inducing factors have been postulated (3-6).

Previous studies have suggested that a decrease in lipoprotein lipase (LPL) activities and an increase in hormone sensitive lipase (HSL) activities contribute lipolysis to cachexia $(4,7)$. LPL hydrolyzes circulating chylomicrons and very low density lipoprotein to fatty acid and consequently helps adipocytes to take up fatty acids as a fat source. HSL hydrolyzes intracellular triglycerides to glycerol and free fatty acids, releasing free fatty acids from adipose tissue into circulation. Therefore, the inability to take up fatty acids due to decreased LPL acitivities and the enhanced degradation of intracellular fats due to increased HSL activities result in a decrease in fat volume, i.e. lipolysis. One would expect that decreased LPL levels and increased HSL activities would increase the serum levels of fatty acids. In fact, several experiments have shown that blood triglyceride levels increased significantly in animal models of cancer cachexia. However, this is not common in cancer patients or always the case, even in animal models of typical cancer cachexia (8-10).

The increased expenditure of resting energy and the enhanced oxidation of fatty acids characteristically observed in cancer cachexia $(11,12)$ suggest that the increased energy demand is supplied by fatty acid oxidation. Therefore, in addition to metabolic alterations that decrease fat volume, there appears to be an acceleration of fat consumption. 
To investigate the metabolic alterations of cancer cachexia, we employed two subclones of colon 26 adenocarcinoma, clone 20 and clone 5 . Clone 20 tumors provoke a severe loss of body weight and storage fat accompanied by a decrease in food intake in syngeneic mice with normal immune function, while clone 5 tumors do not elicit this response (8). In addition, as observed in cancer patients $(9,10)$, the serum triglyceride levels in cachectic mice bearing the clone 20 tumor are not elevated (8). The study of this animal model will provide useful information for understanding the metabolic backgroud of human cancer cachexia.

\section{Materials and methods}

Animals and tumors. Eight-week-old male CDF1 (BALB/c x $\mathrm{DBA} / 2$ ) mice were used. The experimental design followed the Principles of Laboratory Animal Care. Mice were divided into four groups: i) non-tumor bearing (NTB) group, ii) mice bearing clone 5 tumor (clone 5) group, iii) mice bearing clone 20 tumor (clone 20) group and iv) mice inoculated with clone 20 tumor and allowed to drink water containing indomethacin (clone 20 with IND) group.

Two subclones of murine adenocarcinoma colon 26 were used: clone 20 possessed a potent ability to induce lethal cachexia in mice while clone 5 lacked such ability. Cells were grown to subconfluency and were suspended in phosphatebuffered saline (PBS) at a density of $5 \times 10^{6}$ cells ml. An aliquot of cell suspension $(0.2 \mathrm{ml})$, containing either $10^{6}$ cells of clone 20 or clone 5 , was inoculated into the right groin of each mouse.

Following tumor inoculation, body weight (BW) was measured every evening at 5 p.m. Indomethacin (Sigma Chemical Co., St. Louis, MO) was dissolved in ethyl alcohol at a concentration of $10 \mathrm{mg} / \mathrm{ml}$, and $1 \mathrm{ml}$ was added to $1000 \mathrm{ml}$ of drinking water $(0.001 \%)$ which mice were allowed to drink ad libitum. For the assessment of food intake of mice, mice were housed in individual glass metabolic cages with a completely closed system (Sugiyama-Gen, Tokyo).

Extirpation of livers and epididyamal fat pads. Mice were anesthetized with pentobarbital ( $60 \mu \mathrm{g} / \mathrm{g}$ body weight) on day 14 after tumor inoculation. Left epididymal fat pads were extirpated and weighed while wet. Livers were extirpated and were frozen quickly in liquid nitrogen, and then stored at $-80^{\circ} \mathrm{C}$ until used for the measurement of spermidine/ spermine N-1 acetyl transferase (SSAT) expression or determination of Malonyl-coenzyme A (malonyl-CoA) and acetylCoA carboxylase (ACC) levels.

Analysis of the SSAT gene expression by real-time PCR reaction. SSAT expression in murine liver was evaluated by real-time PCR using ABI PRISM 7900 HT Sequence detection system (SDS2.1, Applied Biosystems). The RNA isolation was carried out using an EZ1 RNA Tissue Mini Kit (Qiagen GmbH) in Qiagen Bio-Robot EZ1 (Precision System Science, Japan). After RNA extraction from RAW 264.7 cells or murine liver cells, cDNAs were obtained by reversed transcriptase reactions which were subsequently stored at $-80^{\circ} \mathrm{C}$ until analysis was carried out. Aliquots of $4 \mu \mathrm{l}$ of the cDNA, corresponding to $0.5 \mu \mathrm{g}$ of total RNA, were subjected to real-time PCR in $50 \mu 1$ of final volume containing master mix (SYBR Premix Ex Taq, Code: RR041A, Takara Bio Inc., Japan).

The thermocycling amplification program on a real-time detection system (Bio-Rad) was as follows: $10 \mathrm{sec}$ at $95^{\circ} \mathrm{C}$, 40 cycles at $95^{\circ} \mathrm{C}$ for $5 \mathrm{sec}$ followed by $34 \mathrm{sec}$ at $60^{\circ} \mathrm{C}$. A further melt-curve step (melt-curve) started at $15 \mathrm{sec}$ at $95^{\circ} \mathrm{C}$ followed by $1 \mathrm{~min}$ at $60^{\circ} \mathrm{C}$, and then $15 \mathrm{sec}$ at $95^{\circ} \mathrm{C}$. Amplification products were detected by continuous monitoring of fluorescent release during the SYBR-Green real-time PCR assay. Real-time PCR allows for usage of data from amplifications run in separate tubes to illustrate relative quantization of index DNA normalized with an endogenous control. DNA derived from LPS-treated Raw cells was used as a positive control. For quantitative analysis, the external standard curves were used and the mRNA levels of each target gene were then normalized to those of glyceraldehyde3-phosphate dehydrogenase (GAPDH), an endogenous control gene. The mRNA levels were expressed as SSAT/GAPDH ratios relative to the SSAT/GAPDH ratio of non-tumor bearing mice. SSAT primers (Sigma Genosys, Japan) used were as follows: 5'-ATCTAAGCCAGGTTGCAATGA-3' (forward), 5'-GCACTCCTCACTCCTCTGTTG-3' (reverse). GAPDH primers (Takara Bio Inc.) used were as follows: 5'-TGTGT CCGTCGTGGATCTGA-3' (forward), 5'-TTGCTGTTGAA GTCGCAGGAG-3' (reverse).

Malonyl-CoA measurement. Frozen livers were weighed and transferred to a plastic tube containing a 4-fold weight of $0.3 \mathrm{M} \mathrm{H}_{2} \mathrm{SO}_{4}$, and homogenized for $10 \mathrm{~min}$ on ice. After centrifugation $(10,000 \times \mathrm{g}$ for $10 \mathrm{~min})$, supernatants were measured and transferred to new plastic tubes and adjusted to $\mathrm{pH} 6.5$ on ice using $1 \mathrm{M}$ Tris, $5 \% \mathrm{v} / \mathrm{v}$, then kept at $4^{\circ} \mathrm{C}$.

The measurement of malonyl-CoA was performed as previously described $(13,14)$. At first, acetyl-CoA in the tissue extract was eliminated with citrate synthase in the presence of oxaloacetate (Fig. 1). The samples were mixed with the reaction mixture containing $100 \mathrm{mM}$ oxaloacetic acid, distilled water, cycling buffer $[500 \mathrm{mM}$ Tris- $\mathrm{HCl}$ (pH 7.2) containing $100 \mathrm{mM} \mathrm{MgSO}_{4} .7 \mathrm{H}_{2} \mathrm{O}$ and $10 \mathrm{mM} 2-\mathrm{ME}$ (mercaptoethanol)] and citrate synthase obtained from pig heart in a total volume of $1000 \mu 1$. The samples were incubated for $10 \mathrm{~min}$ at $30^{\circ} \mathrm{C}$, and then $2 \mu \mathrm{l}$ of citrate synthase was added.

After the incubation $\left(20 \mathrm{~min}\right.$ at $\left.30^{\circ} \mathrm{C}\right)$, the cycling was then initiated by addition of $50 \mathrm{mM}$ malonate, $10 \mathrm{mM}$ ATP, and 1.0 unit of malonate decarboxylase and incubated at $30^{\circ} \mathrm{C}$ for $20 \mathrm{~min}$ followed by the addition of 1.0 unit of acetate kinase (Sigma, EC 2.7.2.1). After another incubation for $20 \mathrm{~min}, 2.5 \mathrm{M}$ neutralized hydroxylamine was added and incubation was continued for an additional $20 \mathrm{~min}$ at $25^{\circ} \mathrm{C}$. The reaction was terminated by addition of $10 \mathrm{mM}$ ferric chloride dissolved in $25 \mathrm{mM}$ trichloroacetic acid and $1 \mathrm{M}$ $\mathrm{HCl}$. The absorbance of samples was measured at A540 using a spectrophotometer (Ultraspect 3100 Pro, Amersham Biosciences, UK). The absorbance of samples to which no ezymes were added was also measured. The quantity of acetylhydroxamate formed was estimated by the net absorbance (absorbance of samples with enzymes - absorbance of the same sample without enzymes) (Fig. 1A). The 


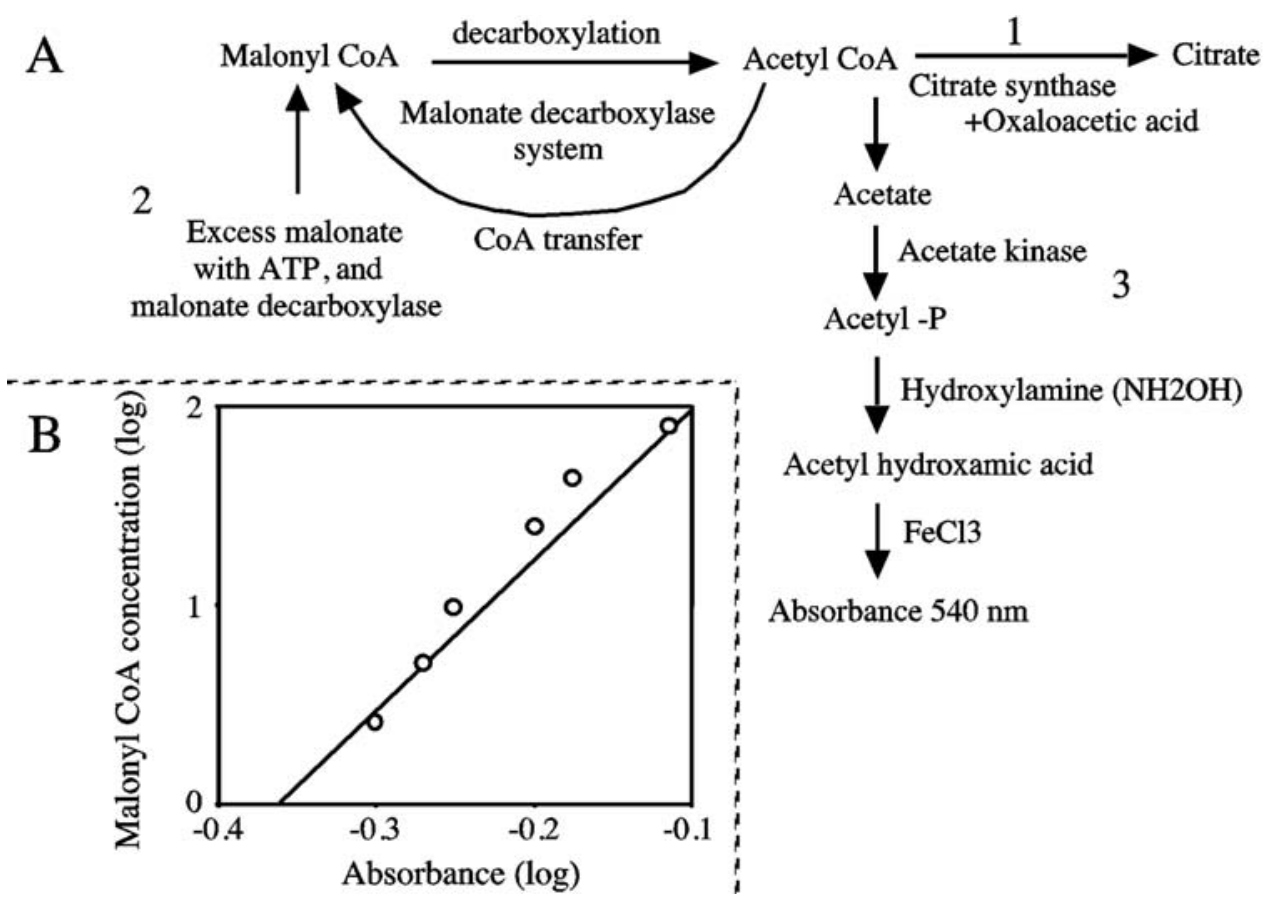

Figure 1. (A) Protocol for malonyl-CoA measurement by malonyl-CoA:acetyl-CoA cycling procedures. 1, Removal of acetyl-CoA by citrate synthase with oxaloacetic acid. 2, Initiation of cycling reaction by adding excess malonate with ATP and malonate decarboxylase. 3 , Measure absorbance of end product. (B) Standard curve for malonyl-CoA created by the malonyl-CoA:acetyl-CoA cycling procedures using purified malonyl-coenzyme A.

concentrations of malonyl-CoA in liver were estimated using a standard curve created with malonyl-coenzyme A (Sigma, USA) (Fig. 1B).

Measurement of acetyl-CoA carboxylase (ACC). Liver (up to $300 \mathrm{mg}$ ) was homogenized in $5 \mathrm{ml}$ of ice-cold $50 \mathrm{mM}$ Tris $\mathrm{HCl}(\mathrm{pH} 7.5), 50 \mathrm{mM} \mathrm{NaF}, 50 \mathrm{mM}$ sodium pyrophosphate, $5 \mathrm{mM}$ EDTA, $5 \mathrm{mM}$ EGTA, $100 \mathrm{mM} \mathrm{Na}_{3} \mathrm{VO}_{4}$, $10 \mathrm{mM}$ HEPES pH 7.4, 0.1\% Triton X-100, $1 \mathrm{mM}$ benzamidine, $0.5 \mathrm{mM}$ phenylmethylsulfonylfluoride (PMSF), and $10 \mu \mathrm{g} / \mathrm{ml}$ leupeptin. Insoluble material was removed by centrifugation and the resulting supernatant used for a Bradford protein assay. Samples as well as Bio-Rad Protein Assay Dye (Standard) were placed on ice. The standard was diluted $0,1.5,2.5,5,7.5$ and 10 times to demonstrate a linear absorbance pattern and protein content in the samples were detected by spectrophotometry.

SDS-polyacrylamide gel electrophoresis (SDS-PAGE) was performed on cell lysate samples (cell lysis buffer: $50 \mathrm{mM}$ Tris- $\mathrm{HCl}, 1 \% \mathrm{NP}-40,0.25 \%$ sodium deoxycholate, $150 \mathrm{mM} \mathrm{NaCl}, 1 \mathrm{mM}$ EDTA, $1 \mathrm{mM}$ PMSF, $1 \mu \mathrm{g} / \mathrm{ml}$ each aprotinin, leupeptin, pepstatin, $1 \mathrm{mM} \mathrm{Na}_{3} \mathrm{VO}_{4}$, and $1 \mathrm{mM}$ $\mathrm{NaF}$ ). Samples in which the same amount of protein was contained were transferred to a nitrocellulose membrane, and the blotted nitrocellulose was washed twice with water followed by pre-blocking with $0.05 \%$ TBS for $10 \mathrm{~min}$. For the measurement of phosphorylated acetyl CoA carboxylase, the blotted nitrocellulose was blocked in freshly prepared TBS containing 5\% non-fat dry milk (TBS-MLK) for $2 \mathrm{~h}$ at room temperature, and then incubated overnight at $4^{\circ} \mathrm{C}$ with $0.5-2 \mu \mathrm{g} / \mathrm{ml}$ of anti-phospho-Acetyl-CoA carboxylase (Serine 79-specific Ab) (Upstate Cell Signaling Solutions, CA, USA) diluted in freshly prepared TBS-MLK containing $0.05 \%$
Tween-20. The nitrocellulose was washed three times with water, incubated in the secondary Ab (Goat anti-rabbit HRP conjugated IgG, 1/5,000 dilution) in TBS-MLK containing $0.05 \%$ Tween-20, for $1.5 \mathrm{~h}$ at room temperature with agitation and rinsed three times with water. For the measurement of total ACC protein, peroxidase-labeled streptavidin (which binds the biotin-containing group of carboxylases) was used. Finally, membranes were washed in TBS-MLK containing $0.05 \%$ Tween-20 for 3-5 min and then washed with distilled water for 1-2 h. Enhanced chemiluminescence (ECL) was used as the detection method. The amount of ACC protein of each sample was assessed by Scion Software Analysis System. The amounts of ACC and phosphorylated ACC were expressed as a percentage relative to the amount of $\mathrm{ACC}$ in non-tumor bearing mice.

Statistical analysis. Data are expressed as means \pm standard deviation (SD). Statistical significance was determined by Student's t-test. P-value levels $<0.05$ were considered significant.

\section{Results}

Changes in body weight, food intake, and epididymal fat weight. As documented in our previous publication, the body weight of mice inoculated with the clone 20 tumor started to decrease rapidly around 10 days after tumor inoculation (8). The decrease in body weight continued to the end of observation, reaching a $21 \%$ decrease compared to the preinoculation value (Fig. 2A). The rapid loss of body weight of mice in the clone 20 group paralleled the marked reduction in food intake (Fig. 2B). In contrast, during the same observational period, mice in the clone 5 group did not 
A

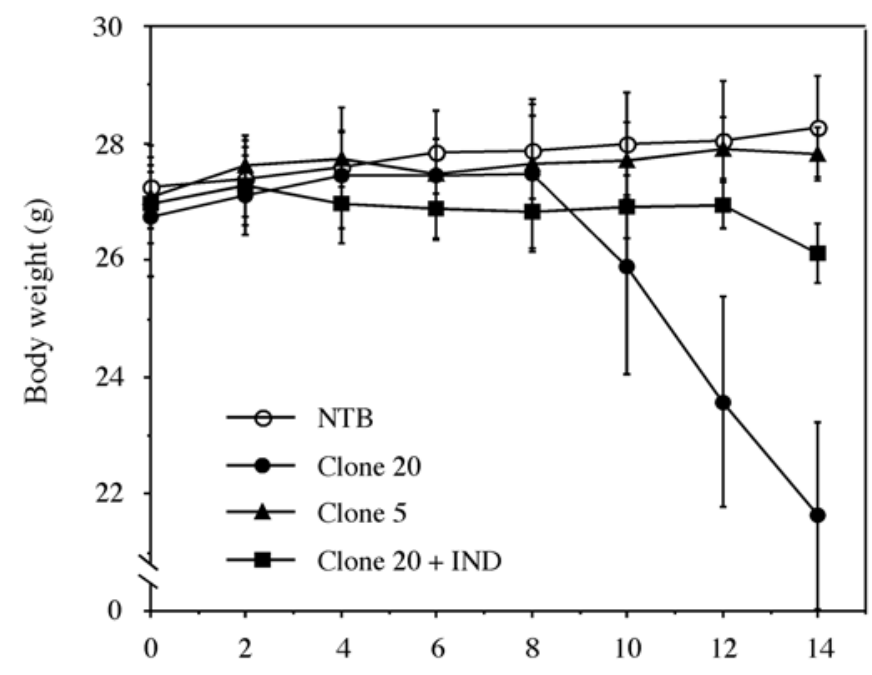

Days after tumor inoculation

Figure 2. Changes of murine body weight (A) and food intake (B) after tumor inoculation. (A) Cells $\left(1 \times 10^{7}\right)$ were inoculated subcutaneously into the right groin of each mouse. Data represent the mean body weight of 6 mice, with bars indicating the standard deviation (SD). Abscissa indicates the number of days after tumor inoculation. (B) Mice were housed individually in closed metabolic cages, and food intake was calculated by subtracting residuals from the initial amount. Data represent the daily food consumption of each mouse. NTB, non-tumor bearing mice; clone 20 , mice bearing clone 20 tumor; clone 5 , mice bearing clone 5 tumor; clone 20 with IND, mice inoculated with clone 20 was treated with indomethacin.

exhibit any cachectic characteristics, and their body weights and food intakes were similar to those of mice in the NTB group. Mice in the clone 20 group initially decreased their food intake approximately ten days after tumor inoculation. Mice in the NTB group and in the clone 5 group did not seem to lose their appetites during observation period. Cachectic manifestations, including body weight loss and decreased food intake, observed in clone 20 mice were almost completely reversed by indomethacin treatment (clone 20 with IND group in Fig. 2).

Cachexia induced by clone 20 was accompanied by a marked decline in the mass of the epididymal fat pad (Fig. 3). Fourteen days after tumor inoculation, the weights of their epididymal fat pads were only $25 \%$ of those in NTB group $(\mathrm{p}<0.01)$. The decrease in fat weight was not observed in mice bearing clone 5 tumor, and those weights were similar to those of non-tumor bearing control mice $(\mathrm{p}=0.83)$. Again, indomethacin treatment completely inhibited the decline in fat weights of mice bearing clone 20 tumor. The weight of epididymal fat pad of mice in the clone 20 with IND group (mice inoculated with clone 20 were treated with indomethacin) was significantly heavier than that of mice in the clone 20 group $(\mathrm{p}<0.01)$, and that in clone 20 with IND group were comparable to those of non-tumor bearing mice $(\mathrm{p}=0.77)$ and those of clone $5(\mathrm{p}=0.93)$ (Fig. 3).

SSAT expression assessed by real-time PCR. SSAT expression was assessed as the SSAT/GAPDH ratio. Using a murine macrophage RAW264.7 cells, we confirmed that LPS
B
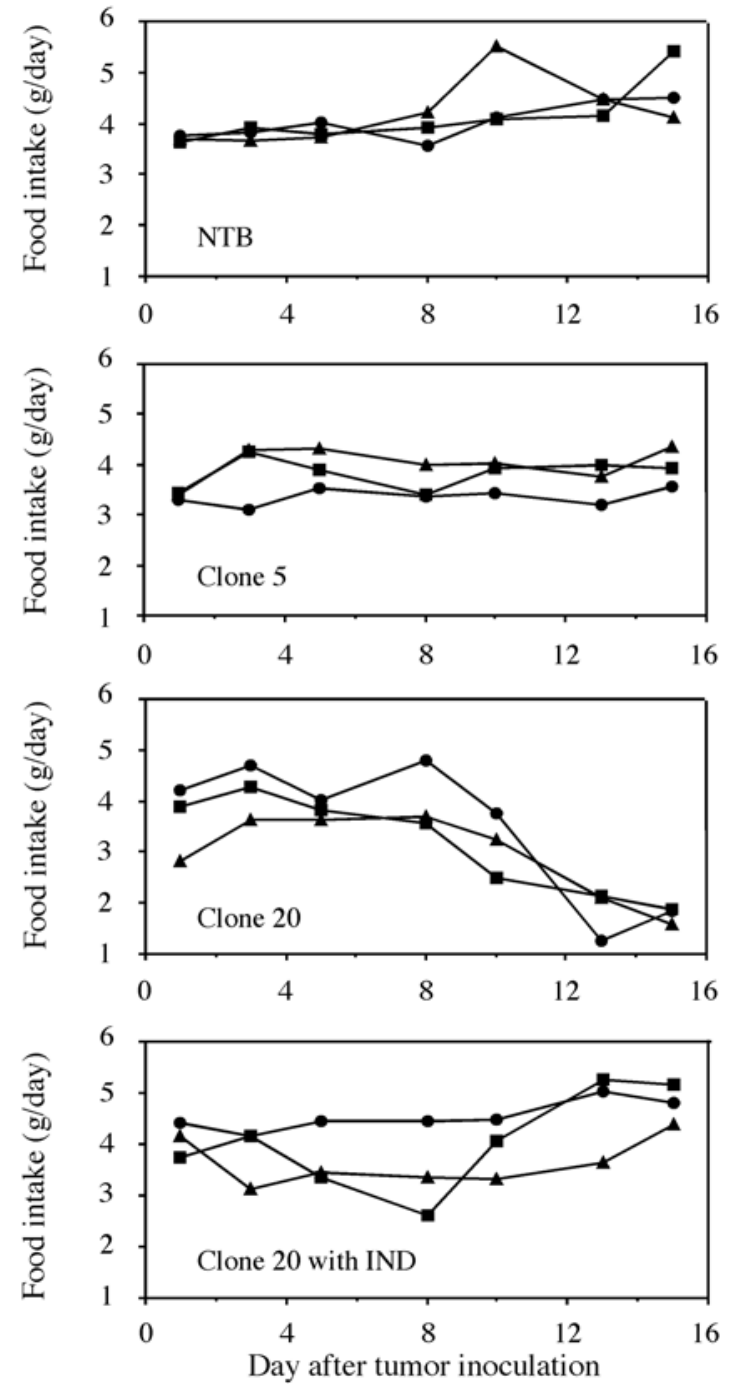

stimulation significantly increased SSAT expression and SSAT/GAPDH ratio compared to non-stimulated RAW cells (data not shown).

SSAT expression in the livers of non-cachectic mice in the clone 5 group was similar to those in NTB group $(\mathrm{p}=0.80)$. In contrast, a marked change was observed in clone 20 mice in which SSAT expression increased considerably (Fig. 4). SSAT expression of mice in the clone 20 group was significantly higher than that of mice in both the NTB group $(\mathrm{p}<0.01)$ and the clone 5 group $(\mathrm{p}<0.01)$. The increase in SSAT expression in cachectic mice bearing clone 20 tumor was significantly suppressed by indomethacin treatment $(\mathrm{p}<0.01)$, and its level was comparable to that of non-cachectic mice bearing clone 5 tumor $(\mathrm{p}=0.29)$ and non-tumor bearing mice $(\mathrm{p}=0.27)$ (Fig. 4).

Malonyl-CoA levels. The decreases in the amounts of liver malonyl-CoA correlated well with the decreases in storage fat. The amounts of hepatic malonyl-CoA in non-cachectic mice bearing clone 5 tumor decreased slightly; however, no significant difference was observed when compared to the NTB group $(p=0.20)$. The amounts of hepatic malonyl$\mathrm{CoA}$ in cachectic mice bearing the clone 20 tumor were 


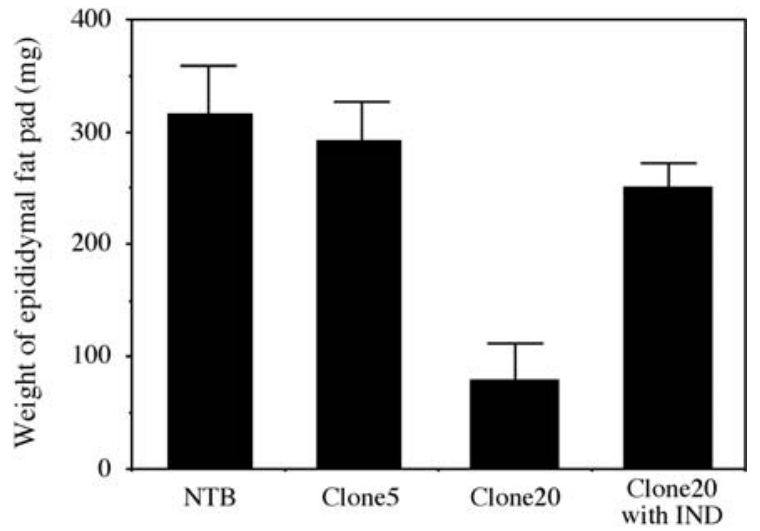

Figure 3. The weight of epididymal fat pads of mice. Fourteen days after tumor inoculation, the left epididymal fat pad was extirpated and weighed while wet. The weight of the epididymal fat pad of mice in the clone 20 with IND group (mice inoculated with clone 20 and treated with indomethacin) was heavier than that of mice in the clone 20 group $(\mathrm{p}<0.01)$. Data represent the mean of six mice with bars indicating SD.

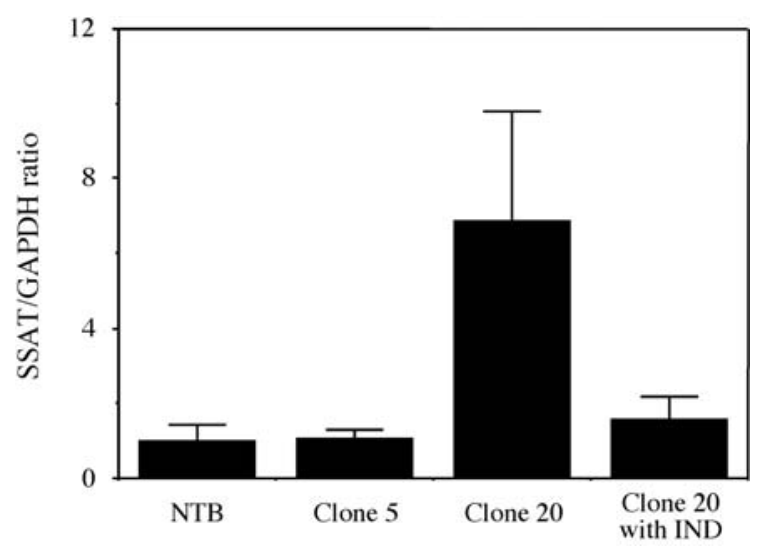

Figure 4. SSAT/GAPDH ratios. SSAT expression was measured by realtime PCR. SSAT expression relative to GAPDH expression is expressed as SSAT/GAPDH. Data are expressed as SSAT/GAPDH ratios relative to the mean values of the SSAT/GAPDH ratio of non-tumor bearing mice. The expression of SSAT/GAPDH of mice in the clone 20 group was significantly higher than the other groups, and the indomethacin treatment significantly suppressed the increase in SSAT expression. Its expression in mice in the clone 20 with IND group was significantly lower than that mice in the clone 20 group $(\mathrm{p}<0.01)$. Each value represents the mean of six mice, with bars indicating SD.

significantly lower than those of mice in both the NTB group $(\mathrm{p}<0.01)$ and the clone 5 group $(\mathrm{p}<0.01)$ (Fig. 5).

Indomethacin treatment of mice bearing clone 20 tumor had the anticipated effects on malonyl-CoA: hepatic levels in that group (clone 20 with IND) were significantly higher than those in clone 20 group $(\mathrm{p}<0.01)$ and comparable to those in mice in the NTB group $(\mathrm{p}=0.26)$ and the clone 5 group $(\mathrm{p}=0.05)$.

Acetyl-CoA carboxylase levels. The amounts of total ACC in the livers of mice bearing either clone 20 or clone 5 tumor were lower than those of mice in the NTB group (Fig. 6). However, the decreases in total ACC levels in cachectic mice in the clone 20 group were more significant $(\mathrm{p}<0.01)$ than those of mice in the clone 5 group $(\mathrm{p}=0.02)$. And the hepatic ACC levels of mice in the clone 20 group were lower than

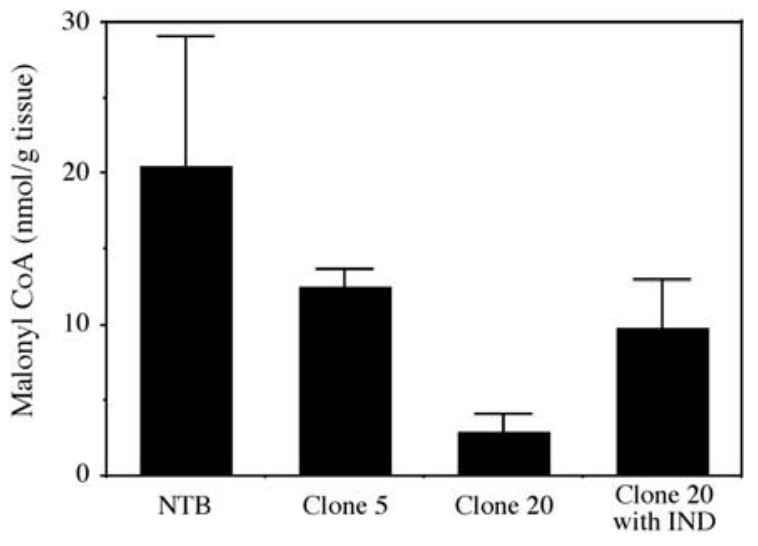

Figure 5. Malonyl Co-A concentration. Malonyl-CoA concentrations were measured by malonyl-CoA:acetyl-CoA cycling procedures described in Materials and methods and in Fig. 2. Malonyl-CoA levels of cachectic mice bearing the clone 20 tumor were significantly lower than those of mice in the NTB or clone 5 groups. Indomethacin significantly inhibited the decline in malonyl-CoA levels, and its levels in the clone 20 with IND group were significantly higher than that of mice in the clone 20 group $(\mathrm{p}<0.01)$. Each value represents the mean of six mice with bars indicating SD.

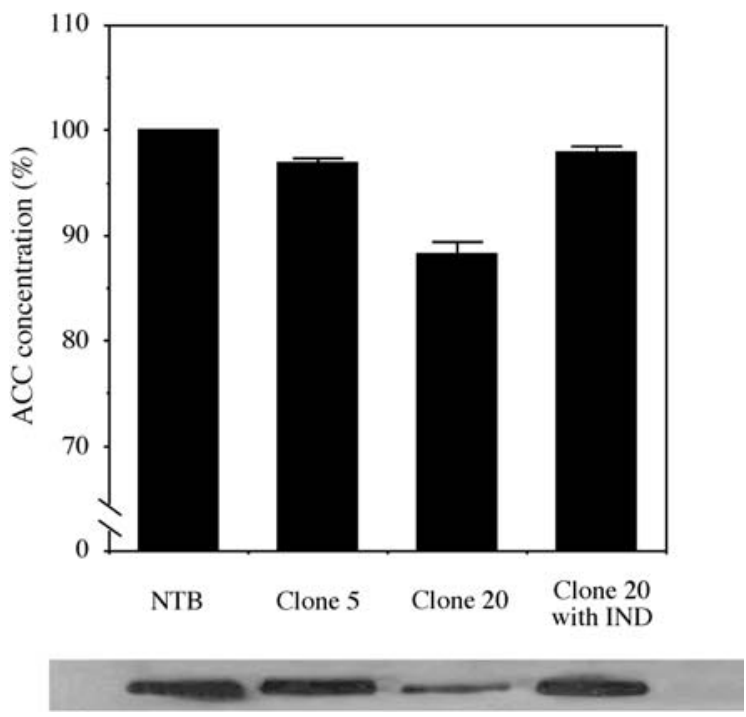

Figure 6. ACC concentration. Upper panel, ACC concentrations were measured by SDS-polyacrylamide gel electrophoresis. The amount of ACC protein of each sample was assessed by the Scion Software Analysis System based on a density profiling program, and the relative amount of ACC was expressed as a percentage relative to the amount of ACC in non-tumor bearing mice defined as $100 \%$. The hepatic ACC concentrations of cachectic mice with the clone 20 tumor were lower than those in the other three groups of mice. Lower panel, a representative of SDSPAGE of total ACC concentration. ACC; acetyl CoA carboxylase.

those of non-cachectic mice bearing clone 5 tumor $(\mathrm{p}<0.01)$. Indomethacin treatment counteracted the decrease in total ACC amounts induced by clone 20 tumor (Fig. 6). The amounts of ACC in liver of mice in the clone 20 with IND group were higher than those of mice in the clone 20 group $(\mathrm{p}<0.01)$.

When comparing the differences of total ACC among the four experimental groups, the differences in phosphorylated ACC levels were not significant. Unlike total ACC, phosphorylated ACC levels in cachectic mice in the clone 20 group 


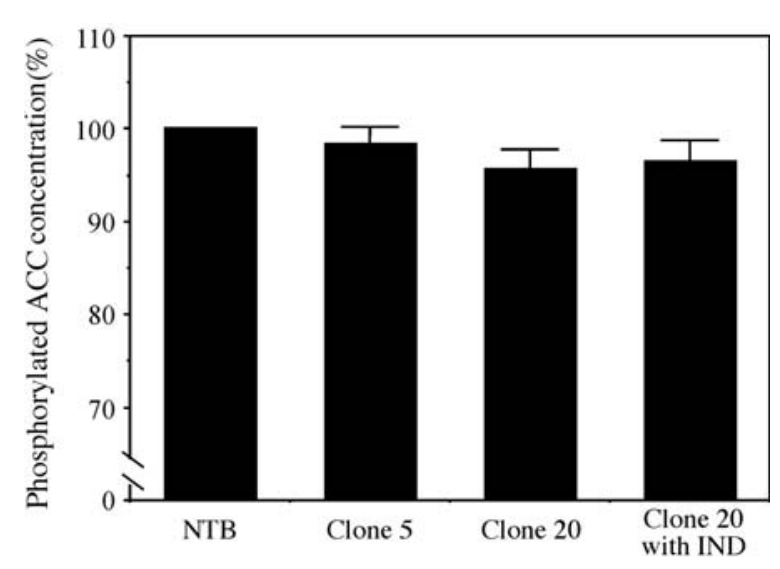

Figure 7. Phosphorylated ACC concentration. Phosphorylated ACC concentrations were measured by SDS-polyacrylamide gel electrophoresis. The amount of phosphorylated ACC protein of each sample was assessed by Scion Software Analysis System based on a density profiling program and the relative amount was expressed as a percentage relative to the amount in mice in the NTB group defined as $100 \%$.

were not dissimilar from those in the NTB $(\mathrm{p}=0.09)$ or the clone 5 group ( $\mathrm{p}=0.29)$ (Fig. 7).

\section{Discussion}

Malonyl-CoA, an intermediate in fatty acid biosynthesis, allosterically inhibits carnitine palmitoyltransferase 1 (CPT 1). CPT1 catalyzes the conjugation of long chain fatty acids and carnitine, and thereby mediates the transport of long chain fatty acids from the cytosol into mitochondria where fatty acid oxidation and degradation occur for the generation of metabolic energy (Fig. 8). Therefore, the decrease in malonylCoA results in an acceleration of the rate-limiting step in the beta-oxidation of fatty acids.
Malonyl-CoA is converted from acetyl-CoA by carboxylation catalyzed by ACC. Because acetyl-CoA, a product of fatty acid oxidation, is a co-factor of SSAT, the continuous SSAT activation leads to the increased demand for acetylCoA. The increased demand for acetyl-CoA by SSAT not only stimulates fatty acid oxidation, but also restricts the availability of acety-CoA as a source of malonyl-CoA. Therefore, the increased SSAT activation and the decreased ACC levels synergistically act to decrease malonyl-CoA levels (Fig. 8).

A recent study has shown decreased amounts of ACC mRNA in adipose tissues of mice suffering cancer cachexia (15). Starvation due to the decreased intake, a manifestation consistently associated with cancer cachexia of human as well as of animal models, decreases hepatic ACC activities both by decreasing ACC mRNA expressions and by increasing ACC phosphorylation (16-18). In cachectic mice bearing the clone 20 tumor, the non-significant decrease in the amount of phosphorylated ACC in spite of the significant decrease in the total ACC amount indicates an increased phosphorylation of ACC. The administration of several pro-inflammatory cytokines profoundly decreases the food intake of animals (19-22), however direct evidence of the inhibitory activities of such cytokines on ACC is sparse. Therefore, the decreased ACC levels are likely due to the anorexia provoked by the factors involved in the pathogenesis of cachexia, while the direct effect of unknown factor(s) is undeniable.

SSAT is an inducible enzyme that catalyzes the transfer of the acetyl group from acetyl-CoA to the terminal amines of spermine and spermidine to prevent toxic over-accumulation of polyamines. SSAT expression and activity are enhanced by increased concentrations of spermine and spermidine that are often observed not only in cancer tissue, but also in normal tissues of tumor-bearing animals and cancer patients. In addition, they are enhanced by oxidative stress, hormones

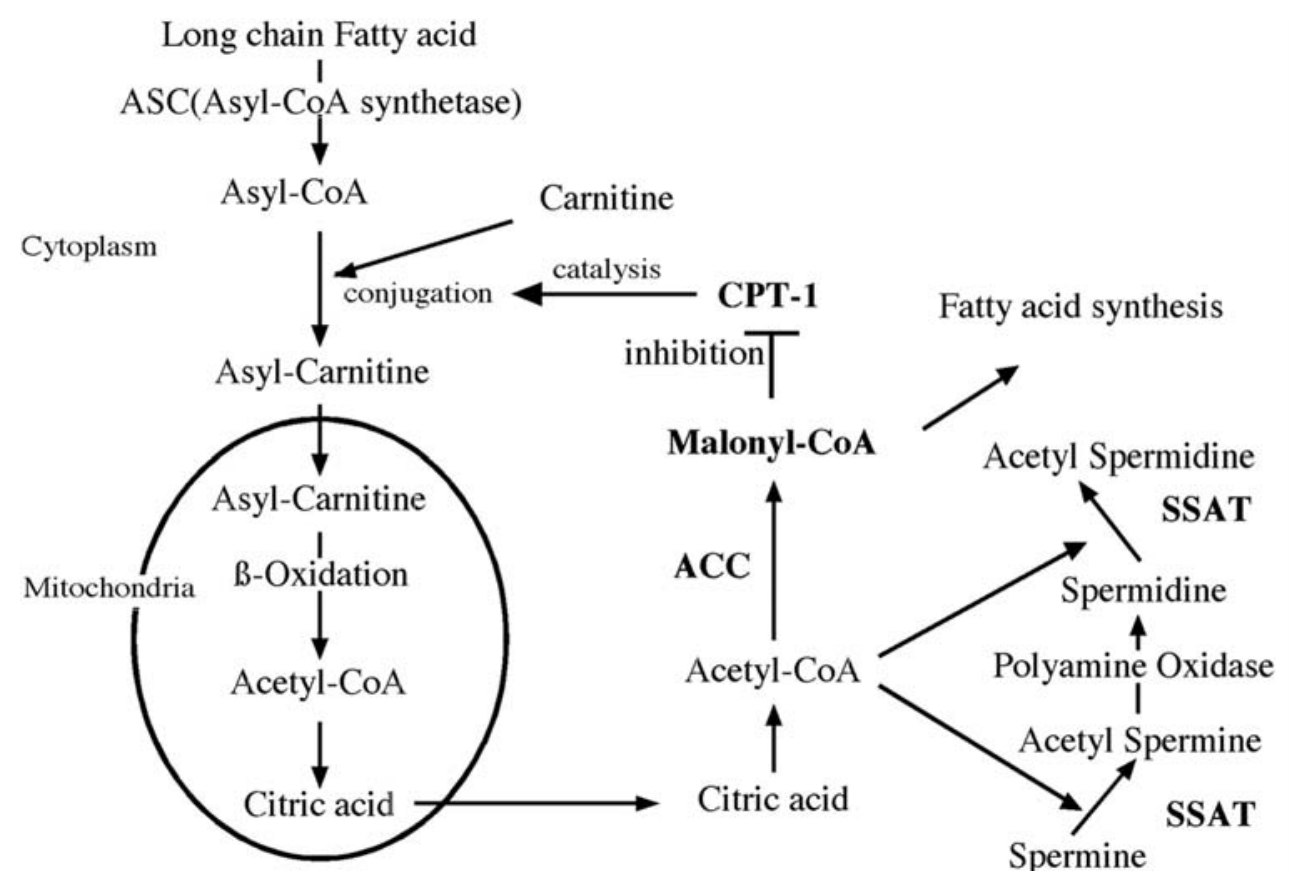

Figure 8. Metabolic schema of fatty acid oxidation. SSAT, spermidine/spermine N-1 acetyltransferase; ACC, acetyl CoA carboxylase; carnitine, 4-hydroxy-3trimethylaminobutyric acid; CPT-1, carnitine-palmitoyl transferase type 1; acetyl-CoA, acetyl coenzyme A; malonyl-CoA, malonyl coenzyme A. 
and several pro-inflammatory cytokines $(23,24)$. Many of these factors are considered to be involved in the mechanism of cancer cachexia $(1,5,8)$. The effects of increased SSAT activities on lipid metabolism have been clearly shown in SSAT transgenic mice in which the amounts of adipose tissue and the pools of acetyl-CoA and malonyl Co-A decrease in association with a major increase in fatty acid oxidation $(25,26)$.

In the mechanism of cancer cachexia, there is numerous evidence of the involvement of inflammation. Indomechacin has been shown to attenuate cachectic events and decrease parameters and mediators of inflammation in animal models of cancer cachexia $(19,27,28)$. However, indomethacin itself stimulates SSAT activities (29). In the clone 20 group, the observation that the increased SSAT expression in cachectic mice was significantly suppressed by indomethacin administration underscores the involvement of inflammatory-associated mediators in the mechanism of cancer cachexia.

Unlike several animal models of cancer cachexia in which a single factor has a crucial role on the pathogenesis of cancer cachexia $(30,31)$, many factors are involved in the mechanism of cancer anorexia-cachexia syndome in humans. Unlike such animal models $(30,31)$, the increase in serum lipid concentration is only exceptionally observed in patients suffering from cancer cachexia. The present study helps in our understanding of the mechanism of lipolysis and the increased fatty acid oxidation in cancer patients suffering from cancer cachexia.

\section{Acknowledgements}

Dr Alper Celik was funded by Turkish Scientific and Technological Research Council (TUBITAK) during his fellowship at Saitama Medical Center, Jichi Medical University.

\section{References}

1. Soda K and Kawakami M: Cancer cachexi, pathogenesis and possible role of cytokines. Ann Cancer Res Ther 3: 73-81, 1994.

2. Brennan MF: Uncomplicated starvation versus cancer cachexia. Cancer Res 37: 2359-2364, 1977.

3. Brooks SL, Neville AM, Rothwell NJ, Stock MJ and Wilson S: Sympathetic activation of brown-adipose-tissue thermogenesis in cachexia. Biosci Rep 1: 509-517, 1981.

4. Kawakami M and Cerami A: Studies of endotoxin-induced decrease in lipoprotein lipase activity. J Exp Med 154: 631-639, 1981.

5. Soda K, Kawakami M, Kashii A and Miyata M: Manifestations of cancer cachexia induced by colon 26 adenocarcinoma are not fully ascribable to interleukin-6. Int J Cancer 62: 332-336, 1995.

6. McDevitt TM, Todorov PT, Beck SA, Khan SH and Tisdale MJ: Purification and characterization of a lipid-mobilizing factor associated with cachexia-inducing tumors in mice and humans. Cancer Res 55: 1458-1463, 1995.

7. Gercel-Taylor C, Doering DL, Kraemer FB and Taylor DD: Aberrations in normal systemic lipid metabolism in ovarian cancer patients. Gynecol Oncol 60: 35-41, 1996.

8. Soda K, Kawakami M, Kashii A and Miyata M: Characterization of mice bearing subclones of colon 26 adenocarcinoma disqualifies interleukin-6 as the sole inducer of cachexia. Jpn J Cancer Res 85: 1124-1130, 1994.

9. Seal US, Doe RP, Byar DP and Corle DK: Response of serum cholesterol and triglycerides to hormone treatment and the relation of pretreatment values to mortality in patients with prostatic cancer. Cancer 38: 1095-1107, 1976.
10. Wallace RB, Rost C, Burmeister LF and Pomrehn PR: Cancer incidence in humans: relationship to plasma lipids and relative weight. J Natl Cancer Inst 68: 915-918, 1982.

11. Popp MB, Brennan MF and Morrison SD: Resting and activity energy expenditure during total parenteral nutrition in rats with methylcholanthrene-induced sarcoma. Cancer 49: 1212-1220, 1982.

12. Legaspi A, Jeevanandam M, Starnes HF Jr and Brennan MF: Whole body lipid and energy metabolism in the cancer patient. Metabolism 36: 958-963, 1987

13. Takamura Y, Kitayama Y, Arakawa A, Yamanaka S, Tosaki M and Ogawa Y: Malonyl-CoA: acetyl-CoA cycling. A new micromethod for determination of acyl-CoAs with malonate decarboxylase. Biochim Biophys Acta 834: 1-7, 1985.

14. Chohnan S and Takamura Y: Malonate decarboxylase in bacteria and its application for determination of intracellular acyl-CoA thioesters. Microbes Environ 19: 179-189, 2004.

15. Bing C, Russell S, Becket E, et al: Adipose atrophy in cancer cachexia: morphologic and molecular analysis of adipose tissue in tumour-bearing mice. Br J Cancer 95: 1028-1037, 2006.

16. Grunfeld C, Verdier JA, Neese R, Moser AH and Feingold KR: Mechanisms by which tumor necrosis factor stimulates hepatic fatty acid synthesis in vivo. J Lipid Res 29: 1327-1335, 1988.

17. Ryu MH, Daily JW III and Cha YS: Effect of starvation on hepatic acyl-CoA synthetase, carnitine palmitoyltransferase-I, and acetyl-CoA carboxylase mRNA levels in rats. Nutrition 21: 537-542, 2005

18. Thampy KG and Wakil SJ: Regulation of acetyl-coenzyme A carboxylase. II. Effect of fasting and refeeding on the activity, phosphate content, and aggregation state of the enzyme. J Biol Chem 263: 6454-6458, 1988

19. Uehara A, Ishikawa Y, Okumura T, et al: Indomethacin blocks the anorexic action of interleukin-1. Eur J Pharmacol 170: 257-260, 1989.

20. Plata-Salaman CR, Oomura Y and Kai Y: Tumor necrosis factor and interleukin-1 beta: suppression of food intake by direct action in the central nervous system. Brain Res 448: 106-114, 1988 .

21. Langstein HN, Doherty GM, Fraker DL, Buresh CM and Norton JA: The roles of gamma-interferon and tumor necrosis factor alpha in an experimental rat model of cancer cachexia. Cancer Res 51: 2302-2306, 1991.

22. Darling G, Fraker DL, Jensen JC, Gorschboth CM and Norton JA: Cachectic effects of recombinant human tumor necrosis factor in rats. Cancer Res 50: 4008-4013, 1990.

23. Casero RA Jr and Pegg AE: Spermidine/spermine N1-acetyltransferase - the turning point in polyamine metabolism. FASEB J 7: 653-661, 1993.

24. Babbar N, Hacker A, Huang Y and Casero RA Jr: Tumor necrosis factor alpha induces spermidine/spermine N1-acetyltransferase through nuclear factor kappaB in non-small cell lung cancer cells. J Biol Chem 281: 24182-24192, 2006.

25. Kee K, Foster BA, Merali S, et al: Activated polyamine catabolism depletes acetyl-CoA pools and suppresses prostate tumor growth in TRAMP mice. J Biol Chem 279: 40076-40083, 2004.

26. Jell J, Merali S, Hensen ML, et al: Genetically altered expression of spermidine/spermine N1-acetyltransferase affects fat metabolism in mice via acetyl-CoA. J Biol Chem 282: 8404-8413, 2007.

27. Tanaka Y, Tanaka T and Ishitsuka H: Antitumor activity of indomethacin in mice bearing advanced colon 26 carcinoma compared with those with early transplants. Cancer Res 49: 5935-5939, 1989.

28. Peluffo GD, Stillitani I, Rodriguez VA, Diament MJ and Klein SM: Reduction of tumor progression and paraneoplastic syndrome development in murine lung adenocarcinoma by nonsteroidal antiinflammatory drugs. Int J Cancer 110: 825-830, 2004.

29. Turchanowa L, Dauletbaev N, Milovic V and Stein J: Nonsteroidal anti-inflammatory drugs stimulate spermidine/spermine acetyltransferase and deplete polyamine content in colon cancer cells. Eur J Clin Invest 31: 887-893, 2001.

30. Sherry BA, Gelin J, Fong Y, et al: Anticachectin/tumor necrosis factor-alpha antibodies attenuate development of cachexia in tumor models. FASEB J 3: 1956-1962, 1989.

31. Nakajima J, Mogi M, Kage T, Chino T and Harada M: Hypertriglyceridemia associated with tumor necrosis factor-alpha in hamster cheek-pouch carcinogenesis. J Dent Res 74: 1558-1563, 1995. 